\title{
Study of Species Lycium L. of Rangeland Ecosystems of Uzbekistan in the Arid Zone Conditions
}

\author{
Nodira Nurullayeva ${ }^{1 *}$, Khislat Khaydarov' ${ }^{1}$, Zebiniso Umurzakova1, D. Imomova ${ }^{2}$, \\ Tolib Mukumov ${ }^{1}$
}

${ }^{1}$ Samarkand State University, Samarkand, Uzbekistan

${ }^{2}$ Jizzakh State Pedagogical Institute, Jizzax, Uzbekistan

Email: *nodira.nurullayeva90@mail.ru

How to cite this paper: Nurullayeva, N., Khaydarov, Kh., Umurzakova, Z., Imomova, D. and Mukumov, T. (2021) Study of Species Lycium L. of Rangeland Ecosystems of Uzbekistan in the Arid Zone Conditions. American Journal of Plant Sciences, 12, 476-485.

https://doi.org/10.4236/ajps.2021.123031

Received: February 9, 2021

Accepted: March 28, 2021

Published: March 31, 2021

Copyright $\odot 2021$ by author(s) and Scientific Research Publishing Inc. This work is licensed under the Creative Commons Attribution International License (CC BY 4.0).

http://creativecommons.org/licenses/by/4.0/

\begin{abstract}
The article presents the features of biology and ecology, growth and development of various Lycium L. species in different ecological conditions of Uzbekistan. The distribution area covers mainly semi-desert and desert zones of Uzbekistan and the description of co-growing coenoses is presented. Based on the study of ecological and biological properties and economically valuable characteristics of Lycium L. species, ecologically significant species were selected as a source material for introduction into culture and use in pharmacology. Useful properties and harms are presented.
\end{abstract}

\section{Keywords}

Fodder Plants, Drought Tolerance, Semi-Deserts, Deserts, Plant

Communities, Yield, Eat Ability, Chemical Compositions

\section{Introduction}

Rational use of rangeland is the main condition for preserving and maintaining the natural potential of natural forage lands, botanical diversity of herbage and increasing their productivity. The variety of types of forage and medicinal plants in Uzbekistan, the identification of resource species, their sustainable use in pasture use and in medicine, as well as the rules for the procurement and storage of medicinal raw materials are currently very relevant. The flora of rangeland of Uzbekistan is very rich and almost all of its representatives have medicinal properties.

As a result of intensive exploitation of rangeland, used without taking into 
account the peculiarities of the bioclimatic potential and unfavorable edaphic conditions, desertification and degradation of the vegetation cover are developing, where biodiversity and productivity decrease accordingly [1]. The demand for medicinal raw materials is constantly growing, but the prospects for using wild-growing species are limited. Overgrazing of livestock, as well as predatory procurement of medicinal plants significantly reduced the supply of raw materials and harvests in natural habitats.

Sustainable use of natural resources of ecologically pure medicinal plants, which are so rich in the ecosystems of Uzbekistan, can become one of the sources of income for the local population.

In addition, the cultivation of medicinal plants with great market potential contributes to the conservation of their diversity. The flora of Uzbekistan numbers more than 577 wild plant species of medicinal value [2]. One of these promising medicinal plants is Lycium species. Various species of Lycium are perennial plants, $1.5 \mathrm{~m}$ or more in height. The areas of their distribution concentrated in the foothills and semi-desert zone of Uzbekistan. The plant is often found in the low mountains, sometimes up to the middle belt of the mountains. Goji (Lycium) is a genus of the Solanaceae family. In Uzbekistan, there are 3 (or 4) species of this plant L. ruthenicum Murray, L. dasystemum Pojark., L. depressum stocs. (L. barbarum L.)

One of these promising medicinal plants is the Lycium species. Various species of Lycium are perennial plants with a height of $1.5 \mathrm{~m}$ and more. The area of its distribution covers mainly the foothill and semi-desert desert zones of Uzbekistan [3].

The plant is often found in low mountains, sometimes up to the middle belt of mountains. Lycium is a genus of the family Solanaceae. There are 3 (or 4) species of this plant growing in Uzbekistan. Lycium barbarum is not poisonous, its fruits are usually dried. In traditional Chinese medicine, fruits are used for dizziness, amblyopia and as a general tonic. Lycium berries can be used as an immune-stimulant, as well as for weight loss, with diabetes mellitus, improves metabolism and slows down skin aging.

Currently, research on the pharmacological properties of Lycium is widely conducted in many countries of the world. Since this plant species is only being introduced into cultivation, there is little information about its ecological and biological characteristics and properties in the literature. Household use Lycium is a honey plant, flowers are visited by bees, collecting nectar and pollen [4].

\section{Beneficial Features}

Provides a source of antioxidants and nutrients. Berries are good for eyesight due to their high levels of antioxidants (especially zeaxanthin). Stabilizes blood sugar levels. Improves reproductive function. Goji (Lycium) berries are low in calories and rich in nutrients and can be safely incorporated into your diet for weight loss. Normalize blood pressure levels. Goji (Lycium) berries are rich in vitamins $\mathrm{B}$ and $\mathrm{C}$, as well as manganese and fiber, all of which boost energy 
levels. Goji berries are anti-inflammatory and may help relieve pain (including pain caused by arthritis).

Normalize metabolic processes in the body. Goji (Lycium) berries are rich in iron. The iron content in this product exceeds its content in buckwheat, apples and spinach. Goji berries are effective in treating infertility. Beneficial nutrients restore reproductive function, improve ovarian function and normalize hormones [5].

\section{Harm}

Goji (Lycium) berries can cause hypertension. They provoke an allergic reaction, for example, gastrointestinal disorders. Eating goji berries can cause indigestion and mild digestive problems in people with a weak digestive system.

\section{Novelty of the Research}

For the first time, a broad study of the coenoses of the co-growth of Licium species in the conditions of the arid zone is provided. Pasture agrophytocenoses, consisting of a mixture of different life forms (shrubs, semi-shrubs, grasses), more efficiently use the water and mineral resources of the environment and more fully meet the requirements of animals for a variety of feed. As a result of the research, materials were obtained on the biological and economic characteristics of various species in the conditions of ecosystems, seed germination, drought resistance and yield of feed and seeds. The results obtained will be used in farms and households farms for the rational use, restoration and increase of productivity of degraded pastures.

\section{Research Goal}

The aim of the work was to study the characteristics of biology and ecology, growth and development of various types of Lycium in various ecological growing conditions. Development of scientific and practical foundations for the adaptive use of agroecological resources, included optimization of the flora composition, assessment of biological diversity and identification of the resource potential of natural vegetation.

\section{Material and Methods of Research}

During the research, the following methods were used: Description of vegetation, taking into account its floristic composition, was carried out according to the Drude method generally accepted in geobotany. Clarification of the area was carried out on the basis of literature data and surveys of distribution areas within the Samarkand, Bukhara, Surkhandarya regions. Age-related changes in plants according to the method of T.A. Rabotnov (1964). Phenology was carried out according to the method of I.N. Beideman (1974). The plant species was specified according to S.K. Cherepanov (I995) and Keys to Plants of Central Asia (v. IX, I968-993) [6] [7] [8] [9]. 
To determine the amount of carbohydrates in the samples, the necessary equipment and standard substances: Agilent 1200 liquid chromatograph, Degasser G1379A device with degasser, QuatPump G1311A pump, ALS G1313A motor sampler, Colcom G1316A column thermostat, RID refractometric detector. SupelcosilLC-NH2 5-micron speaker $4.6 \times 250 \mathrm{~mm}$, Supelco, USA. Pipette volume up to 100 and $1000 \mu \mathrm{l}$ VWR, Poland. $5 \mathrm{ml}$ pipette, Biohit, Finland. Analytical scales AnD GR-202 (accuracy 0.00001 g), “AnD”, Japan. Deionized water Millipore Simplicity, "Millipore", France. Ultrasonic cleaner Elmasonic S 30 H, "Elma", Germany. Nylon filter 0.45 microns $13 \mathrm{~mm}$. Fructose standard, imp. Glucose standard, UTI. Sucrose standard, imp Standard of maltose monohydrate, acetonitrile "Sigma-aldrich" for USSX (HPLC), USA.

In the process of working out the method, the following analysis conditions were determined: isocratic elution mode, the composition of the mobile phase acetonitrile/water in the volume ratio $82 / 18$ without mixing around two separate containers. The composition of the mobile phase may vary to achieve complete separation of the glucose and fructose peaks. Volume elution rate $1.0 \mathrm{ml} / \mathrm{min}$; injection volume $10 \mathrm{mcl}$; column thermostat temperature $35^{\circ} \mathrm{C}$; standard retention time: fructose $-4.9 \pm 0.2 \mathrm{~min}$, glucose $-5.7 \pm 0.2 \mathrm{~min}$, sucrose $-10.4 \pm 0.2$ min, maltose $-12.1 \pm 0.2 \mathrm{~min}$.

\section{Results and Discussion}

The current status of grasslands in arid zone and formation of growth species.

Pastures of Bukhara region are mainly divided into 4 economic types:

1) Semi-shrub-herbaceous type

2) Ephemeral type

3) Shrub-herbaceous type

4) Saltwort vegetation type

The main vegetation on the rangelands of the Bukhara region: Artemisia diffusa Krasch. ex Poljakov, Haloxylon persicum Bunge, Astragalus villosissimus Bunge, Cousinia sp., Convolvulus hamadae (Vved.) Petrov, Carex pachystylis J.Gay and Poa bulbosa L. The total vegetative cover 55\% - 75\%.

Saltwort vegetation type of rangelands. Under the conditions of 2020, on the pastures of the Bukhara region (Photo 1), the average yield of fodder by the seasons of the year was $0.27-0.35 \mathrm{t} / \mathrm{ha}$ on this type of pasture, which are recommended for use in spring, summer and autumn [1]. Climacoptera lanata (Pall.) Botsch., Alhagi maurorum Medik., Salsola scleranthum (C.A.Mey.) Akhani \& Roalson, Haloxylon persicum, Astragalus villosissimus Bunge. The average height of plants is $25-35 \mathrm{~cm}$, Haloxylon persicum is $1.5-2.5 \mathrm{~m}$.

Haloxylon persicum type of rangelands. The average yield of fodder by the seasons was $0.20-0.21 \mathrm{t} / \mathrm{ha}$. Year-round rangelands [1]. Vegetation is Haloxylon persicum, Salsola richteri (Moq.) Akhani \& Roalson, Climacoptera lanata (Pall.) Botsch. The height of Haloxylon persicum and Xylosalsola richteri (Moq.) Akhani \& Roalson is 2.5 - $3.5 \mathrm{~m}$, Climacoptera lanata is $35-45 \mathrm{~cm}$ (Photo 2(a) and fruits of Lycium ruthenicum (Photo 3)). 


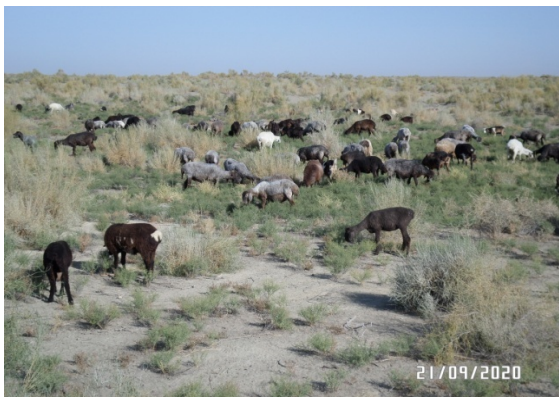

(a)

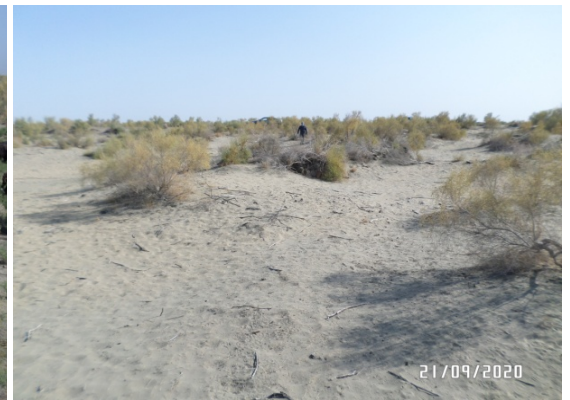

(b)

Photo 1. State of rangelands in Bukhara region 2020.

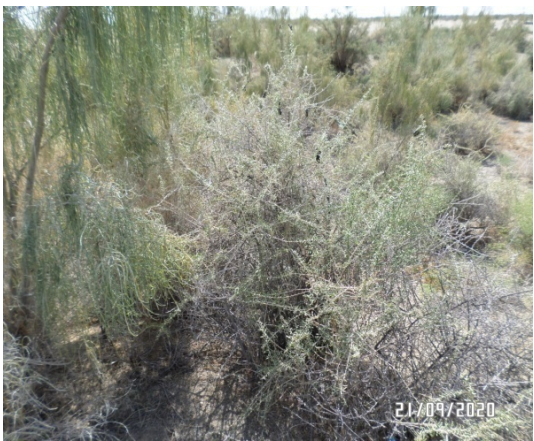

(a)

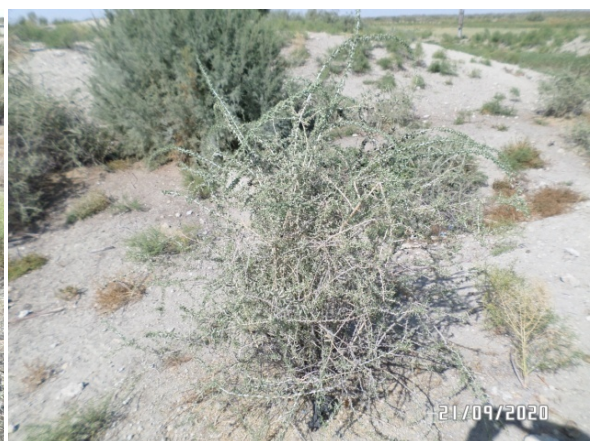

(b)

Photo 2. (a) Haloxylon persicum formation; (b) Tamarix hispida formation.

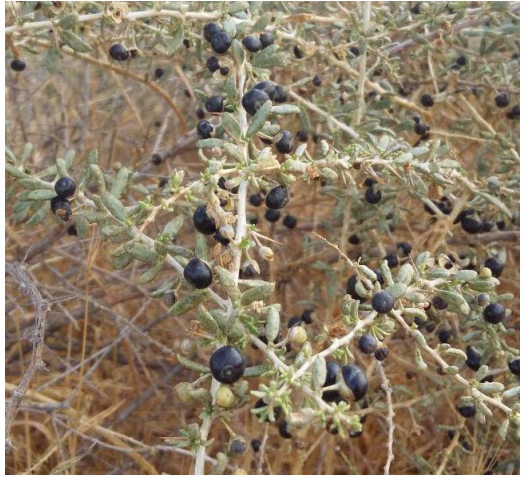

(a)

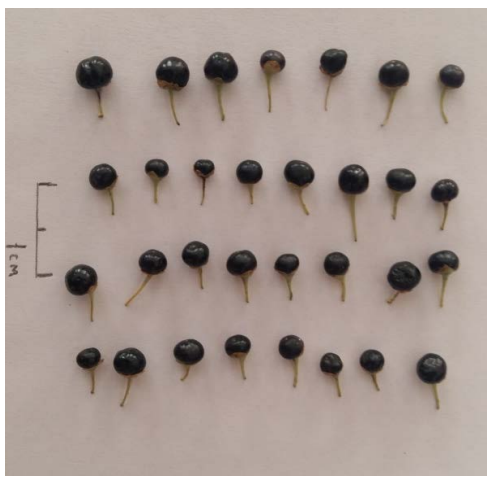

(b)

Photo 3. Fruits of Lycium ruthenicum.

In the described ecosystems around the sheep flock in the Bukhara region Dzhondor district N 3944098 E 06347557 alt 205 m, pasture vegetation is represented by the following species: Alhagi maurorum, Aeluropus litoralis, Salsola praecox, Haloxylon persicum, Tamarix hispida, Lycium dasystemum, shrub height $2.5-3.5 \mathrm{~m}$, rough grass $35-40 \mathrm{~cm}$. Projective cover $45 \%-50 \%$.

The soil is desert-sandy, the planned texture along the profile is $0-15 \mathrm{~cm}$, highly silty aeolian sand, below up to $100 \mathrm{~cm}$, slightly silty aeolian sand, the surface is covered with salt spots. The predominant land use is pasture. Edible plants-3. Seed formation-2, Alhagi pseudalhagi, Salsola praecox. Average rainfall for this year. 
Tamarix hispida formation (Photo 2(b)). Bukhara region Dzhondor district N 3943'59.5"E 06349240 alt 202 m.s.l., vegetation of Tamarix hispida, Alhagi pseudalhagi, Lycium ruthenicum Murr. The height of Alhagi pseudalhagi plants is $35-45 \mathrm{~cm}$, Tamarix hispida $3.5 \mathrm{~m}$, Lycium ruthenicum-1.5 - $2.5 \mathrm{~m}$. Projective cover $45 \%-60 \%$. The soil is desert-sandy from the accumulation of eolian sand, medium-thick from a depth of $70 \mathrm{~cm}$, often pieces of siltstone and sandstone. The surface is dirty whitish faint salt colors. This area is close to the groundwater table.

Indicator stripes of meso- or hydrophytic vegetation are associated with the ascending movement of fresh or low-mineralized waters; in this area, it includes deep-rooted plants of the genera Tamarix and Lycium. They quickly grow as root suckers, form impassable thickets. Livestock eats them only in spring, when the thorns are not strong. The predominant land use is pasture. Edible plants-2. Seed formation-2, Alhagi maurorum, Lycium ruthenicum [10]. Samples of Lycium were tested under culture conditions, the types of which are presented in Table 1.

Phenological observations in culture for the samples were carried out in 2018-2020. The onset and duration of developmental phases depend primarily on the biological characteristics of plant species, but also depend on whether temperature and precipitation. In L. barbarum in Uzbekistan, the growing season begins much earlier, in the third decade of February, L. dasystemum-in the first decade of March, L. ruthenicum, L. depressum-in the second decade of March. Vegetation in individual growing seasons underwent changes depending on temperature in different years.

At the beginning of the growing season of plants, various vegetative and generative buds develop on the branches. Vegetative buds are located in a row in the lower, middle and upper parts of the branch, generative-in the axils of the vegetative buds. The size of the buds is different. Buds at the base and middle of the branch are much larger (length $3.5-5.5 \mathrm{~mm}$, width $2.5-3.2 \mathrm{~mm}$ ).

The biological feature of these species lies in the fact that on one plant you can see both the buds being formed, and flowers that have not yet blossomed, and not yet ripe and ripe fruits. That is, the buds form on the top of the branch, while the fruit ripens at the bottom of the branches. The duration of flowering in these species lasts from spring, summer to late autumn. Lycium gives fruit (Photo 4) from May to October (depending on the region).

Table 1. Tested specimens of wolfberry in culture.

\begin{tabular}{|c|c|c|c|c|}
\hline \multirow{2}{*}{ № } & \multirow{2}{*}{ Species of Lycium } & \multirow{2}{*}{ Regions } & \multicolumn{2}{|c|}{ Coordinates } \\
\hline & & & $\mathrm{N}$ & $\mathrm{E}$ \\
\hline 1 & L. barbarum L. & Samarkand (research areas & $39^{\circ} 38^{\prime} 54.6^{\prime \prime}$ & $66^{\circ} 57^{\prime} 56.5^{\prime \prime}$ \\
\hline 2 & L. ruthenicum Murray & Samarkand Bukhara & $\begin{array}{c}39^{\circ} 39^{\prime} 47.86^{\prime \prime} \\
39^{\circ} 44^{\prime} 09.8^{\prime \prime}\end{array}$ & $\begin{array}{l}66^{\circ} 57^{\prime} 56.5^{\prime \prime} \\
63^{\circ} 47^{\prime} 55.7^{\prime \prime}\end{array}$ \\
\hline 3 & L. dasystemum Pojark. & Samarkand & $39^{\circ} 45^{\prime} 36.47^{\prime \prime}$ & $66^{\circ} 42^{\prime} 31.40^{\prime \prime}$ \\
\hline 4 & L. depressum Stocs & Surkhandarya & $37^{\circ} 41^{\prime} 18.48^{\prime \prime}$ & $67^{\circ} 00^{\prime} 52.67^{\prime \prime}$ \\
\hline
\end{tabular}




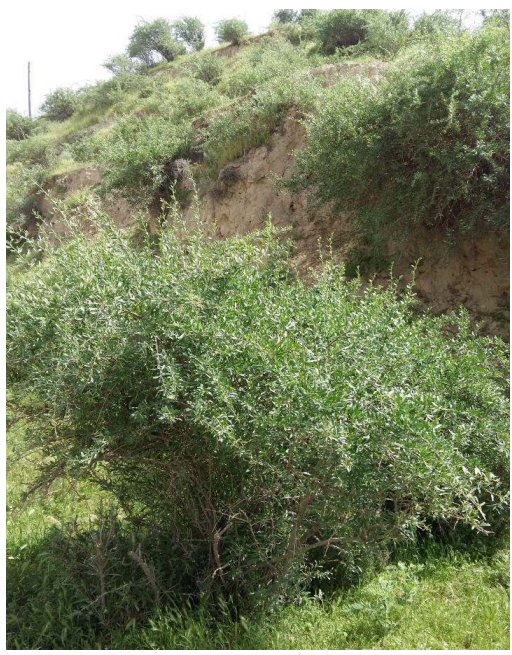

(a)

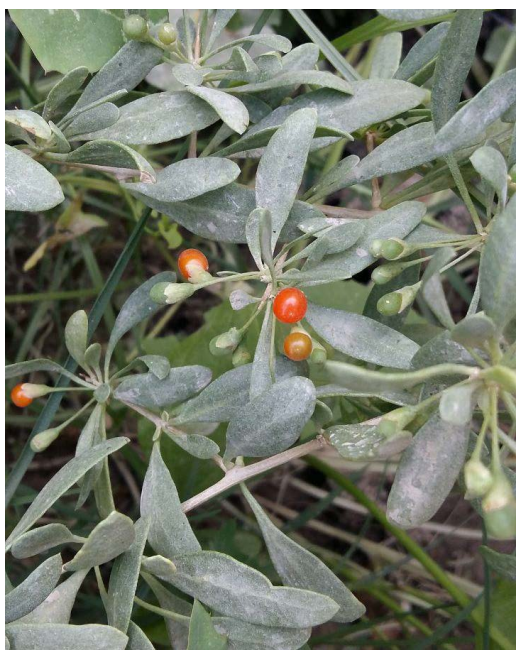

(b)

Photo 4. General view and fruiting phase of $L$. dasystemum Pojark.

In July, L. dasystemum species have a small dormant period when the plant ends its growing season. In the second decade of August, new leaves begin to form on the plant again and the growing season continues. In other species, the leaves fall off at the base of the main stems, but do not stop the vegetation of the plants. This feature is characteristic of xerophytic species, in which leaf fall in hot and dry summers and transition to dormancy is the plant's response to an external stress factor, indicating the breadth of the adaptive potential to the environment.

L. barbarum begins to ripen in late May - early June. In November, some of the leaves on the branches turn yellow, and some turn green until the first snow falls.

These species of the family Lycium L. also develop root suckers. In three to four years old plants, offspring develop on the roots and form new branches. $L$. depressum (Photo 5) height 1.5 - $2.5 \mathrm{~m}$, bare prickly bush, branches are hard, strong, spread in all directions, cracked bark, annual stems are thin, stems are often bent, bark is light. Fruits are red, spherical or ovoid, $4-8 \mathrm{~mm}$ long. Seeds are $2-3 \mathrm{~mm}$ long. It grows in the Surkhandarya region of Uzbekistan.

Determination of the amount of carbohydrates in food, that is, monosaccharides, is carried out using high performance liquid chromatography. For this, if the detected sample contains fatty substances, it is defatted and a certain amount is removed from the defatted substance. The resulting sample is extracted with water and placed in an ultrasonic water bath for a specified period of time to speed up the extraction process.

At the end of the extraction process, it is filtered or centrifuged and quantified using high-performance liquid chromatography (HPLC) as the superdeposition liquid (liquid part). The studies were conducted in accordance with the Guidelines for Quality Control and Safety of dietary supplements [11].

As can be seen from Table 2, the total amount of carbohydrates was the highest-77.07 $\mathrm{mg}$ in L. barbarum and the lowest-49.24 $\mathrm{mg}$ in L. ruthenicum. 


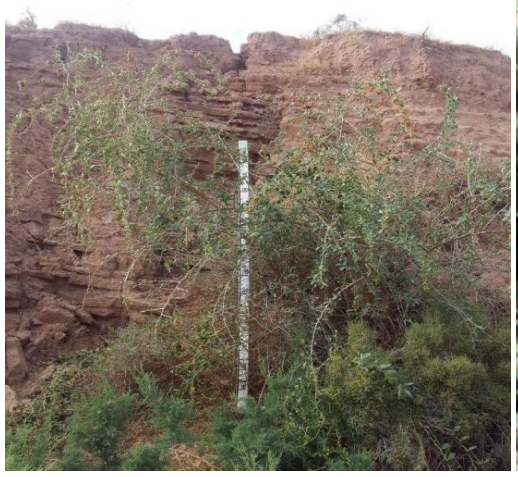

(a)

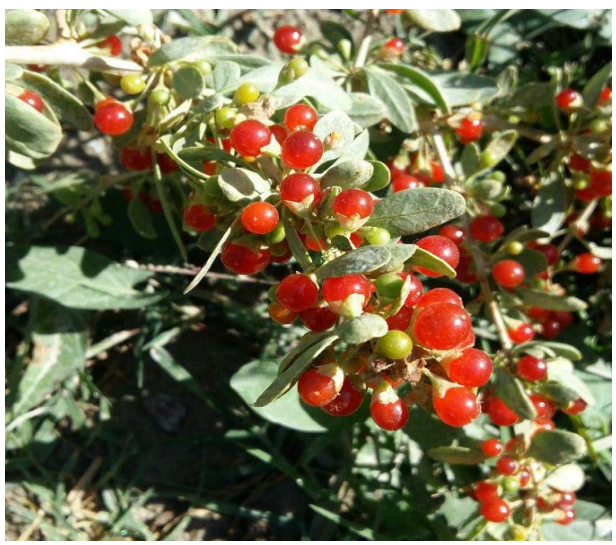

(b)

Photo 5. General view and fruiting phase of L. depressum Stocks.

Table 2. The amount of carbohydrates in some species of the Lycium genus.

\begin{tabular}{ccccc}
\hline \multirow{2}{*}{ Carbohydrates } & L. depressum & L. ruthenicum & L. dasystemum & L. barbarum \\
\cline { 2 - 4 } & \multicolumn{4}{c}{ Concentration $\mathrm{mg} / \mathrm{ml}$} \\
\hline Fructose & 22.37 & 13.32 & 33.07 & 33.6 \\
Glucose & 27.72 & 35.61 & 42.41 & 43.02 \\
Sucrose & 1.20 & 0.21 & 0.60 & 0.45 \\
Maltose & 0.76 & 0.10 & 0.10 & 0.00 \\
The amount & $\mathbf{5 2 . 0 4}$ & $\mathbf{4 9 . 2 4}$ & $\mathbf{7 6 . 1 8}$ & $\mathbf{7 7 . 0 7}$ \\
\hline
\end{tabular}

Chemical composition. Common Lycium berries are rich in vitamins (riboflavin, thiamine, ascorbic acid), minerals (zinc, selenium, magnesium, iron, chromium, calcium, phosphorus), carotenoids (beta-carotene, zeaxanthin). They contain steroid saponins and flavonoids, many amino acids, and the alkaloids hyoscyamine [12] [13] [14].

\section{Conclusions}

Based on the study of ecological and biological features and economically valuable characteristics of pasture plant species of the natural flora of Uzbekistan, ecologically significant species were selected as a source material for introduction into culture and use in pharmacology.

The widespread introduction of valuable types of wood used as medicinal and forage plants will allow the creation of breeding nurseries. Growing medicinal plants that have a large market potential helps to preserve their diversity and generate additional profit. The results obtained can be used in farms and karakul farms to restore and increase the productivity of degraded pastures, especially in the Republic of Karakalpakistan, and use them as medicinal raw materials. Wood species (Lycium) are good forage plants for improving degraded pastures, fixing broken sands in the Kyzylkum desert and in the Aral Sea region.

Potential consumers of the research results are karakul sheep breeding and 
farming enterprises of the arid zone, the Agency for the Development of the Pharmaceutical Industry under the Ministry of Health of the Republic of Uzbekistan, and the NGO "Vaccine". In folk medicine, the fruit of the shrub is used for various diseases.

It should be noted that wood is a perennial plant, so the main production costs are necessary only in the first year of plant life, and in subsequent years when using crops, they are minimal.

\section{Conflicts of Interest}

The authors declare no conflicts of interest regarding the publication of this paper.

\section{References}

[1] Granitov, A.I. (1980) Methodological Guidelines for the Geobotanical Survey of Natural Forage Lands of Uzbekistanp. 170. (In Russian)

[2] Khalmatov, Kh. (1964) Wild Medicinal Plants of Uzbekistan. Medicina, Tashkent. 3-7. (In Russian)

[3] Khaydarov, Kh., Mukimov, T., Islamov, B. and Nurullayeva, N. (2020) Biological Features and Productivity of Drought-Tolerant Fodder Plants under the Conditions of the Adyr Zone of Uzbekistan. International Journal of Scientific and Technological Research, 6, 34-38.

[4] Kovalevskaya, S. (1961) Flora of Uzbekistan V Volume. Academy of Sciences of the Uzbek SSR, Tashkent, 429-434. (In Russian)

[5] Potterat, O. (2010) Goji (Lycium barbarum and L. chinense): Phytochemistry, Pharmacology and Safety in the Perspective of Traditional Uses and Recent Popularity. Planta Medica, 76, 7-19. https://doi.org/10.1055/s-0029-1186218

[6] Czerepanov, S.K. (1995) Vascular Plants of Russia and Adjacent States (the Former USSR). Cambridge University Press, New York, 152.

[7] Rabotnov, T.A. (1950) Life Cycles of Perennial Grass Plants in Meadow Populations. Transactions of Institute of Botany of Academy of Sciences of USSR, Geobotany, Moscow, Leningrad, 176.

[8] Beideman, I.N. (1974) Methods for Studying the Phenology of Plants and Plant Communities. Nauka, Novosibirsk, 153 p.

[9] Serebryakov, T.I. (1981) Life Forms and Models of Shoot Formation of Ground-Creeping Perennial Grasses. Life Forms: Structure, Spectra and Evolution Reports of the Academy of Sciences, Moscow, 161-179.

[10] Farmanov, T., Mukhtorov, A. and Mukimov, T. (2020) Improvement of Degraded Pastures in the Foothills and Sandy Desert Zone of Uzbekistan by Implementing Best Practices. International Journal of Scientific and Technological Research, 6, 143-149.

[11] Eller, K.I. and Pimenova, V.V. (2004) A Guide to the Methods of Quality Control and Security Biologically Active Additives to Food. The Manual R 4.1.1672-03. Moscow, $239 \mathrm{p}$.

[12] Yao, X., Peng, Y., Xu, L.J., Li, L., Wu, Q.L. and Xiao, P.G. (2011) Inform Abstract: Phytochemical and Biological Studies of Lycium Medicinal Plants. Chemistry \& Biodiversity, 8, 976-1010. https://doi.org/10.1002/cbdv.201000018 
[13] Qian, D., Zhao, Y., Yang, G. and Huang, L. (2017) Systematic Review of Chemical Constituents in the Genus Lycium (Solanaceae). Molecules, 22, 911.

https://doi.org/10.3390/molecules22060911

[14] http://www.plantsoftheworldonline.org/ 